\title{
Os estudos sobre o corpo para além da apologia e da negação: contraposição crítica ao pós-modernismo
}

\section{Body studies beyond apology and denial: critical dissent against post-modernism}

\author{
Herold Jr. Carlos ${ }^{1}$
}

\begin{abstract}
RESUMO
O objetivo deste estudo é problematizar as abordagens pós-modernas em relação ao corpo e à corporeidade. Para isso, dividimos o texto em três momentos: no primeiro, mostramos a forma como a forte presença acadêmica das análises sobre o corpo, está relacionada ao nascimento e ao desenvolvimento das concepções pós-modernas de ciência e filosofia; no segundo, apontamos as principais características e contradições dessa abordagem do corpo; no terceiro, a partir de alguns estudos de base materialista histórica, lançamos algumas possibilidades para que esse objeto seja analisado também por esse referencial. Como conclusões, evidenciamos a necessidade de abordagem materialista da corporeidade em que tanto a apologia quando a recusa da temática, sejam evitadas.

Palavras-chave: corpo; corporeidade; materialismo histórico; pósmodernismo.
\end{abstract}

\begin{abstract}
The aim of this study is to question post-modern approaches on the body and corporeality. For that, we divided the text in three different moments: firstly, we show the way the body studies and their steady academic presence are closely related to the arising and development of post-modern
\end{abstract}


ideas on science and philosophy; after that, we specify some features and contradictions regularly found in the body studies whose basis is postmodernism. In the third part, we built some possibilities to deal with this subject having historical materialism as support. As conclusions, we could verify that a materialist approach on body is really necessary and also that both the apology and the bald refusal concerning body and corporeality must be avoided.

Key-words: body; corporeality; historical materialism; post-modernism.

\section{Considerações iniciais}

A forte presença acadêmica de estudos sobre a questão do corpo acaba por criar dificuldades para apreensão e diferenciação entre as positividades e as negatividades passíveis de serem analisadas no processo. Isso se manifesta, na maioria das vezes, ou em uma apologia ou em uma condenação sumária sobre os estudos em torno da corporeidade. De um lado, posicionam-se os teóricos que ao tematizarem as questões do corpo, imputam a essa tentativa uma maneira de crítica e ultrapassagem de "todos" os limites da modernidade. De outro, há a postura dos intelectuais que enxergam nessa empreitada mais um "modismo", mais uma tentativa de simplificar questões mais complexas que seriam, necessariamente, mais sérias, de interesse público e/ou estruturais.

Grosso modo, de um lado, poderíamos agrupar esses posicionamentos teóricos como atinados ao que se chama de pós-modernismo, que sustentam e elogiam unidirecionalmente a "retomada do corpo" para a discussão da sociedade hodierna. Villaça e Góis (1998) apresentam de forma resumida a configuração dos estudos sobre a corporeidade no interior do pós-modernismo:

Os teóricos contemporâneos se empenham em caminhos variados que optam pelos hinos aos avatares naturalistas, por versões neo-iluministas de controle, por movimento libertários do corpo, seja como organismo (linha nietzchiana), seja como campo de forças (Deleuze). Opções pelo corpo hedonista e narcísico no contexto da cultura do consumo (Lipovetsky), delação das estratégias de controle nas suas mais diversas formas com propostas de micropolíticas defensivas (Foucault), reflexões sobre o corpo do consumo de viés neomarxista (Featherstone, Canclini), versões das novas apropriações do corpo alienado no consumo (Eagleton) ou tiradas apocalípticas sobre o fim da corporeidade na simulação total (BAUDRILLARD, p. 42). 
No polo oposto, estão aqueles que, com base na análise da sociedade capitalista feita a partir de uma determinada leitura de Marx, imputam aos estudos do corpo a pecha de serem estudos que se afundam em um subjetivismo descritivo e que, em última instância, redundaria na negligência dos problemas econômicos e políticos. Um exemplo dessa consideração é apresentado por Konder (1998) que, quando nos aponta a mesma consideração sobre a necessidade da discussão sobre a corporeidade, não concorda, no entanto, com a abordagem de Eagleton:

Outro exemplo pode ser encontrado no modo sardônico como Eagleton aborda a revalorização da corporeidade por autores pós-modernos. No entanto, Eagleton debocha do que chama de "saracoteios carnavalescos" do "discurso do corpo". E força um gracejo que aproxima a ginástica de Jane Fonda e a reflexão de Michel Foucault para descrever um movimento de degradação realizado a partir do abandono de Che Guevara! A frase é: "O socialismo de Guevara cedeu lugar à somatologia de Foucault e Fonda" (s.p).

Temos como pressuposto que o ecletismo, sustentado na vulgar ideia de "meio termo", não é uma boa alternativa para sair do impasse. O que defendemos é que há a necessidade de uma discussão mais detida sobre o assunto e que as duas vertentes analíticas acima, ao assumirem apressadamente ou a apologia ou a negação, não colaboram para o aprofundamento do debate que deveria explicar de que maneira as relações sociais e as idiossincrasias subjetivas se relacionam e, ainda, de que maneira elas impulsionam ou retardam determinadas transformações na sociedade e sobre quais critérios.

Como resultado, essas formas de análise deixam intocados aspectos relevantes para a tarefa acima esboçada e o preço a ser pago, além da incompreensão em torno da temática é a contradição no interior de suas análises que, na maioria das vezes, tocam até equívocos passíveis de serem diagnosticados no âmbito da lógica formal.

O cerne das limitações desses estudos, assim como das possibilidades para superá-las é o debate em torno da construtividade do corpo e da corporeidade, e sua relação com a materialidade natural, assim como caráter histórico desse relacionamento. Dito de outra maneira, tanto a apologia quanto à recusa temática da corporeidade elaboram teses que discutem o quê e como o processo de formação social e pessoal dos indivíduos tem de transitório e/ou de perene. Para dar conta de problematizar essas questões, dividimos o texto em três 
momentos: no primeiro apontamos a relação do surgimento da corporeidade com o referencial pós-moderno. No segundo verificamos qual é a característica desse tipo de análise. No terceiro, verificamos alguns posicionamentos no âmbito do marxismo que, indo na contracorrente de outros analistas do mesmo referencial, assumem a corporeidade como assunto a ser estudado. A guisa de conclusão, esboçamos algumas considerações para fazer com que as possibilidades de uma análise materialista e histórica da corporeidade possam ser assumidas.

\section{O desenvolvimento dos estudos do corpo e o pós-modernismo}

Com as transformações que aconteceram na sociedade a partir da década de 1960 e que tiveram seus ritmos acelerados nas décadas subsequentes, surgiu um conjunto de concepções políticas, filosóficas e estéticas que são respeitadas as diferenças entre elas, agrupadas sob a denominação de pós-modernistas. Jameson (2000) e Anderson (1999) analisam a história desse processo e verificam a necessidade de observarmos as dificuldades de adjetivar claramente o que é o pós-modernismo, haja vista a existência de ideias e práticas opostas, críticas entre si, mas que caberiam na mesma alcunha.

De forma geral, como já sinalizava Lyotard (1979), um dos pilares da concepção pós-moderna de ciência e filosofia é a critica às "grandes narrativas", vistas como desenvolvidas e praticadas na modernidade e que, no século $\mathrm{XX}$ teriam sido as grandes causadoras de guerras e mortes. A base da crítica às grandes narrativas, tornou-se a explicitação dos limites e do autoritarismo da ciência, que passou a ser evidenciada pelo seu caráter discursivo, pragmático e social, em que a tão almejada objetividade, que em nome da verdade redundaria em uma sociedade livre, nada mais seria que uma "construção discursiva".

Os objetos de análise, a partir daí, tornaram-se mais localizados, específicos, pois eles conteriam neles mesmos, lógicas próprias, riquezas idiossincráticas que seriam impossíveis de serem captadas por análises que privilegiassem a "totalidade social". O que se queria buscar era o concreto, as tramas e os conceitos que eram feitos e refeitos em cada interação social, diferentes em várias nuances, de acordo com os infinitos relacionamentos.

No interior desse processo, um dos objetos que passou a ser extremamente recorrente foi o estudo das questões concernentes ao corpo. E esse desenvolvimento se deu em um duplo sentido: primeiro pela crítica ao pensamento moderno graças ao lugar subalterno atribuído do corpo e, em segundo lugar, pela relevância que a corporeidade passou a ter em estudos nas mais variadas áreas 
que passaram a concebê-la como o locus no qual a busca da possibilidade de construir uma vida pessoal com sentido se daria. Afirma Mcnally (2001, p. 02) "conversa do corpo está em todo lugar no discurso pós-modernista".

Na primeira vertente de estudos sobre o corpo, sobretudo, a crítica ao dualismo entre corpo e mente tornou-se um dos principais pontos para a problematização da herança filosófica da modernidade. Descartes fora eleito o responsável pelos séculos de instrumentalização corporal em favor da inteligência, que passou a ser vista como "demasiadamente" racionalista, passando a razão também a ser tomada como fonte das mazelas, vistas agora, principalmente, como produzidas e sentidas no âmbito pessoal. No momento em que as utopias sociais de construção de uma sociedade livre, justa e fraterna passaram a serem vistas como coisas do passado, o foco sobre o corpo veio como a possibilidade de se buscar a felicidade individual em meio a fatos que ao serem estudados sem a "arrogância" moderna, passaram a serem adjetivados como incompreensíveis e incontroláveis, não valendo a pena a reflexão e a construção de uma possibilidade de mudança.

Para viabilizar a colocação do corpo como elemento central para a construção de vidas significativas, tratou-se, assim, após "desconstruir" a imagem moderna sobre o corpo e suas relações com as outras dimensões da subjetividade, e, após ter-se verificado que essas ideias longe de serem fatos eram discursos, ocuparam-se os estudiosos de elaborar uma grande quantidade de trabalhos que assumiram o caráter histórico das imagens sobre o corpo e da corporeidade, sendo a própria constituição biológica vista como passível de ser superada a partir do momento em que sua materialidade deixasse de ser vista como tal.

A positividade dessas análises não pode ser negada. Elas possibilitaram, entre outras coisas, a base para a crítica feminista ao caráter não necessário das relações de gênero, marcadas pela dominação da masculinidade. A feminilidade e a masculinidade tornaram-se valores e comportamentos a serem estudados não pelas ciências biológicas e médicas, mas sim pela história e antropologia, que evidenciaram seus traços construídos, históricos e transitórios que formam a base discursiva para que as diferenças sociais, econômicas e política entre os sexos, com base na anatomia corporal, acontecessem e fossem criticadas.

$\mathrm{Na}$ educação de uma forma geral e na educação física de maneira mais específica, a partir da década de 1980, essas constatações impactaram também os processos de construção educativa da corporeidade, o que provocou uma intensa revisão de prática, métodos e valores relacionados a diversos processos pedagógicos em que a dimensão corpórea passara a ser vista como constitutiva de práticas educacionais, sendo esse conjunto de reformulações facilmente observável pelo menos no meio acadêmico. 


\section{O pós-modernismo e as diferentes formas de análise do corpo}

Ao focalizarmos os caminhos percorridos pelas análises do corpo desenvolvidas no pós-modernismo, vemos que a multiplicidade de opções acaba girando em torno da construtividade ou da essencialidade corporal humana.

Como já frisamos, o fato de se sublinhar o caráter histórico e transitório das representações, dos usos, dos sentimentos e do valor da corporeidade representou um grande avanço. Ela serviu para fazer frente às análises que não atribuem ao corpo um assunto a ser investigado pelas ciências humanas e pela história. Até então, o corpo era tomado em sua materialidade biológica e deveria como tal, ser analisado.

A ênfase no caráter construído da corporeidade evidenciou também a forma como ela fora secundarizada na história, na filosofia e nas ciências humanas. Ao mesmo tempo, mostrou-se que mesmo sendo ela vista como algo inferior e menor, ela esteve presente nas mais variadas formas nas várias sociedades, exercendo um papel visto como subterrâneo graças aos jugos da razão, no entanto, com mais importância do que poderiam conceber as "ingenuidades" do "poder" racionalista.

Na história, o corpo passou a ser um objeto privilegiado nas várias obras que surgiram analisando a história cotidiana e dos grupos marginas da sociedade. $\mathrm{Na}$ filosofia, obras e teses foram elaboradas para evidenciar que o preconceito racionalista havia deixado os analistas cegos para a presença do corpo em múltiplas temáticas. Nas ciências humanas, a constituição mesma da possibilidade da vida em sociedade passou pelos laços que, para existirem e funcionarem na cotidianidade, são sustentados pelo corpo e pela corporeidade. Nesse sentido, afirma Gil (1997, p. 14):

\footnotetext{
Assiste-se actualmente, depois do esforço psicanalítico, a uma verdadeira invasão do culto ao corpo [...] Muito estranhamente, na mesma altura em que esta voga testemunha uma sensibilização crescente pelos problemas do corpo tendente a afirmar sua importância nos mais diversos domínios, retomam-se velhas ideias, velhos esquemas - idênticos aos regimes de signos que serviram para a exploração do corpo: este tornou-se o significante despótico que resolverá tudo, desde o declínio da cultura ocidental, até aos menores conflitos intra-individuais.
} 
De um lado, essa reformulação acadêmica fez com que nos meios de comunicação as questões concernentes à saúde, ao bem-estar, e à beleza, fossem transformadas em uma prática social facilmente constatável em várias classes e realidades, em que as pessoas envolvidas no seu alcance almejavam construir uma vida com mais significado ao valorizar seus próprios sentimentos, sua sensações, enfim, sua corporeidade. A "saúde perfeita" como diz Sfez (1996), transformou-se num mito cultuado, adorado e definidor de projetos de vida, influenciando novas formas de tratamento e cuidado corporais, que, justamente por isso, passaram a serem adjetivados de "alternativos".

Se o boom das academias desportivas na década de 1980 foi uma outra manifestação desses fatos com a proliferação de várias modalidades de ginástica e práticas, na década de 1990 e depois do ano 2000, as atividades corporais alternativas, passaram a serem vistas por um grande contingente de praticantes como o caminho para o desenvolvimento e o conhecimento de sua integralidade, tudo com base e inspirado em filosofias orientais e em terapias psicológicas que assumiam o corpo como a base de suas atividades (MATTHIESSEN, 1999).

Um outro fenômeno bastante frequente é o desenvolvimento das tecnologias médicas que, além das aplicações terapêuticas viabilizadas, culminou na possibilidade pessoal de "construir" o próprio corpo por base de cirurgias e implantes. A insatisfação com o próprio corpo, desde que consolada com as condições financeiras adequadas, poderia ser rapidamente resolvida.

Uma outra forma em que o corpo passa a ser altamente valorizado é na questão do consumo. Se levarmos em conta a crise do capitalismo após a década de 1970 e a necessidade sempre renovada de se encontrar novas formas e motivos para a produção e o consumo, notamos que o corpo e seu cuidado tornaram-se altamente "valorizados". Braudrillard (2005), por exemplo, ao definir o que ele chama de sociedade do consumo, relaciona suas reflexões sobre a importância do consumo defendendo que o corpo assume no interior do processo uma importância central:

Na panóplia do consumo, ele é um objeto o mais bonito, mais precioso, mais vibrante que todos $-[\ldots]$ é o corpo. Sua redescoberta, depois de uma era milenar de puritanismo, sob o sinal da liberação física e sexual, sua onipresença (e especificamente do corpo feminino, é preciso ver porquê) na publicidade, na moda, na cultura de massa [...] tudo testemunha que o corpo, hoje, tornou-se um objeto de redenção (BRAUDRILLARD 2005, p. 200). 
Por outro lado, no interior do mesmo processo de valorização ao corpo que aconteceu tanto nas variadas especialidades acadêmicas quanto na prática social cotidiana, começou a haver uma tendência a se advogar uma desvalorização do corpo e da corporeidade. O mote mais recorrente dessa desvalorização, extremamente coadunada com as ideias que advogam a existência de uma "sociedade do conhecimento", é a limitação da materialidade corporal perante as tecnologias da informação. Baudrillard (1999, p. 57), um dos analistas mais lidos a respeito, afirma:

O que será do Outro quando ele desaparecer? O que se torna o Real, o que se torna o corpo quando eles foram substituídos pela sua fórmula operacional? O que se torna o sexo, o trabalho, o tempo e todas as outras figuras da alteridade, quando elas caem sob o golpe da síntese tecnológica?

Mais à frente, ele responde a todas essas questões: "Assim, a arte, o trabalho a religião e o corpo esqueceram de morrer” (BAUDRILLARD, 1999, p. 60).

Sibília (1998) observa como o ideário do pós-humano se enraíza na virtualidade das informações, impedidas de circularem e se reproduzirem graças à ancoragem no "real" proporcionada pelo corpo. Os projetos das mais variadas ordens, partindo das ciências da informação, passando por expressões artísticas, chegando até movimentos de caráter religioso passam a defender a superação do corpo.

Como afirmam Jameson e Anderson, o pós-modernismo não aceita definições e classificações. A condução das análises sobre corpo que redunda tanto na sua valorização quanto na sua execração, pode ser encontrada em Baudrillard (1999, p. 61), que mesmo afirmando a necessidade de se "enterrar o corpo", afirma:

Todavia, os mortos, mesmo virtuais, vingam-se. O tempo abolido dentro do tempo real se vinga sob forma de milenarismo delirante ou sob forma de pesquisa desesperada pelas origens. A natureza, reduzida a uma fonte de energia se vinga sob a forma de catástrofes naturais. $\mathrm{O}$ corpo experimentado no virtual se vinga sob a forma de virtualidade de patologias auto-imunes. 
Reconhecemos a relevância que esses posicionamentos com base no pósmodernismo possuem, desde que assumamos com Anderson $(1999$, p. 78$)$ que "Uma crítica autêntica do pós-modernismo não podia ser uma recusa ideológica dele. Ao contrário, a tarefa dialética era abrir caminho por meio dele de forma tão completa que nosso entendimento da época emergisse transformado". Além disso, como diz Konder (1998):

Complexo e contraditório como é, o pós-modernismo não só expressa a realidade social fragmentada do presente, legitimando-a, mas também corporifica, em inúmeros aspectos, uma atitude de insatisfação, de rebeldia implícita em face dela, trazendo algumas observações agudas que nos ajudam a compreendê-la (s.p.).

Acreditamos que a valorização dos estudos da corporeidade no seio do pós-modernismo é uma positividade. Por outro lado, para que as análises não encetem as aporias acima apresentadas, é necessário direcionar a análise do corpo e da corporeidade para uma outra direção, não mais com base nos pressupostos pós-modernistas.

Tendo por base outros autores que também enxergam o mesmo fato, notamos a necessidade de se abordar a questões do corpo e da corporeidade direcionando-a para problemas concernentes aos impasses do capitalismo hodierno.

\section{$O$ contra-ponto às análises pós-modernistas do corpo}

A constatação dessas contradições deve estimular a busca de caminhos analíticos que possibilitem que a positividade do crescimento dos estudos sobre o corpo e a corporeidade produza condições para que a nossa compreensão das problemáticas atuais e passadas aconteçam de forma mais crítica.

Os estudos sobre o corpo, ao enfatizarem o caráter discursivo, histórico e de objeto necessário para o estudo das questões nas mais variadas disciplinas, acabaram construindo a grande quantidade de obras e estudos enfatizando a crítica, entre outros, aos limites do marxismo.

Por outro lado, sem querermos ainda afirmar a existência de uma abordagem marxista da corporeidade e dos estudos do corpo, podemos observar que 
uma quantidade importante de análises partindo da consideração das obras de Marx existe e merece ser estudada.

Uma das primeiras questões que afligem os estudiosos marxistas que desenvolvem estudos sobre o corpo, é o esvaziamento desses estudos das questões concernentes às relações e as mediações entre a subjetividade e as questões objetivas que, no caso do referencial marxista, tocam as transformações e as lutas políticas em torno do trabalho. Harvey (2000), por exemplo, esforça-se para analisar a questão da corporeidade e da globalização das relações sociais de produção capitalista, em um mesmo movimento. Para o autor americano, uma consequência concreta dessa opção é encarar a problemática do corpo com vistas às lutas políticas para a transformação da sociedade:

O estudo do corpo tem que se basear na compreensão das relações espaço-temporais concretas entre práticas materiais, representações, imaginários, instituições, relações sociais e estruturas vigentes de poder político-econômico. Pode-se então ver o corpo como um nexo por meio do qual abordar possibilidades de uma política emancipadora (HARVEY, 2000, p. 178).

Essa "política emancipadora" da qual fala Harvey tenta abordar uma das contradições mais limitadoras do pós-modernismo no entender de Frigotto (1998), Jameson (2000) e Lessa (2005), esse referencial, ao apoiar-se nos estudos culturais, enfatizando o caráter construído do corpo e ao afirmar a transitoriedade de todos os valores e análises, acabam por endossar, por outro lado, o caráter perene das relações sociais capitalistas de produção. Ou seja, o surgimento e o desenvolvimento das análises sobre o corpo, que se deram sob a bandeira de luta contra as visões teleológicas, acaba por endossar o "fim da história".

A possibilidade das críticas ao pós-modernismo e suas abordagens do corpo reside, de acordo com Harvey (2000), Mcnally (2001) e Mooers (s.d.), em um estudo acurado que ambicione empreender uma compreensão mais crítica sobre as relações entre nossa corporalidade e a cultura, mediadas pelas relações sociais de produção em dado momento.

Tendo por base essa constatação, Mcnally (2001) observa que a importância que se vem dando ao corpo é um meio de negar a sua materialidade, encarando-o como "discursivo". Para o autor essa é a forma mais presente de um novo idealismo cujo discurso pós-modernista é o grande exemplo.

Essa negação da materialidade corporal é vista como um resultado intrigante do reconhecimento da construção cultural do corpo, que de acordo com 
Hacking (apud MCDONAGH, 2004), exacerba o cartesianismo contra o qual lutam. Tendo por base esse processo, o autor conclui pelo fato de que no interior do pós-modernismo e no seu recorrente motivo antidualista, acabou-se tomando o cartesianismo numa radicalidade que nem o próprio Descartes, talvez, teria imaginado como possível (BAKER; MORRIS, 2002). Mooers (s.d., p. 22) vai ao encontro dessa análise quando expressa: "Transformando o corpo em uma abstração discursiva o pós-modernismo meramente retoma o dualismo mente/ corpo dos tempos anteriores".

Essas considerações acabam por ter resultados que explicitam a forma como o pós-modernismo analisa a alteridade (cuja desconsideração é uma das principais fontes de crítica ao referencial marxista feitas pelos pós-modernos), agora não mais "reduzida" à de classe, mas concernente ao gênero e à etnia. Harvey (2000) tem claro que a de Marx não desenvolveu todas as possibilidades para a análise da corporeidade. As ausências sobre questões sexuais, de gênero, raça, entre outras, por sua vez, não inviabilizam a obra de Marx como uma das bases para que o estudo da corporeidade e da alteridade se dê com a captação de suas vinculações sociais mais amplas:

Por conseguinte, há uma multiplicidade de outros processos - metabólicos, ecológicos, políticos, sociais e psicológicos - que desempenham funções essenciais com relação a práticas e possibilidades corporais. Mas essas ausências não podem ser sanadas por meio do apagamento seja do método, seja da substância da abordagem de Marx. [...] Marx proporciona um rico aparato conceitual para a compreensão de processos de produção e ação corporal no âmbito do capitalismo. E tem quase a mesma importância o fato de ele oferecer uma epistemologia apropriada (tanto históricogeográfica como dialética) para abordar a questão de como os corpos são produzidos, de como vêm a ser os significantes e referentes de significados e de como práticas corporais internalizadas poderiam em contrapartida modificar os processos de produção do eu nas condições contemporâneas da globalização capitalista (HARVEY, 2000, p. 159).

Mooers (s.d., p. 17) também nota que não é esse o caminho percorrido pelas correntes filosóficas com base nas tendências pós-modernistas, afinal elas enxergam a "descorporificação" como um sinônimo de emancipação. Afinal: "Liberados dos constrangimentos da corporeidade, pode ser pensado, que nós poderíamos também ser liberados de várias formas de discriminação corporal expressas no racismo e sexismo".

Feitas essas advertências e estabelecida à necessidade de conectar as 
questões do corpo e da corporeidade com os dilemas concernentes à transformação ou a manutenção das relações sociais capitalistas de produção, a seguinte advertência de Eagleton é um bom começo para se buscar uma compreensão da corporeidade, evitando que os estudos sobre o corpo padeçam dos limites apresentados:

É importante não nos vermos, como o pós-modernismo costuma fazer, como criaturas "culturais" em vez de "naturais", mas como seres culturais em virtude de nossa natureza, o que equivale a dizer em virtude dos tipos de corpos que temos e do tipo de mundo a que pertencem (EAGLETON, 1993, p. 74).

Devemos não perder de vista, dessa forma, que o "tipo de mundo" que temos é o construído pela exploração privada do trabalho coletivo, com base nas relações sociais de produção capitalistas, historicamente construídas e também ultrapassáveis.

\section{Considerações finais}

Os dilemas e limitações apontados no interior do pós-modernismo quando ele é utilizado para entabular as questões sobre o corpo, devem servir também como advertência aos analistas que, ao criticarem o pós-modernismo, negam a importância de algumas temáticas trazidas por esse referencial. Sobre isso, Konder (1998), ao falar sobre as resistências do marxismo em relação à corporeidade, afirma que "Há, sem dúvida, muito a se discutir sobre o assunto. Para que a discussão seja esclarecedora, no entanto, o caminho melhor não é o da desqualificação de uma posição pela outra" (s.p.).

Wood (1999), ao analisar as relações entre pós-modernismo e história, elenca uma gama importante de temáticas abordadas por esse referencial, entre as quais está a corporeidade. Após isso, ela defende que "Nenhum de nós pretende negar a importância de alguns temas pós-modernistas" (WOOD, 1999, p. 17).

Consoante a esse tipo de atenção, e em concordância com Eagleton (1993), acreditamos que a "retomada do corpo foi uma das mudanças mais importantes no pensamento radical recente" (EAGLETON, 1993, p. 11). O que queremos, ao advertir sobre as formas e limites das análises que correntemente são feitas 
sobre o corpo e a corporeidade é o esforço em estabelecer "extensão desta fértil tendência de investigação numa nova direção" (EAGLETON, 1993, p. 11) E para isso, a utilização das ferramentas analíticas desenvolvidas pelo materialismo histórico são de grande importância para fazer uma contraposição crítica ao limites pós-modernistas.

\section{REFERÊNCIAS}

ANDERSON, P. As origens da pós-modernidade. Rio de Janeiro: Jorge Zahar Editor, 1999.

BAKER, G.; MORRIS, K. Descartes' Dualism. London and New York: Routledge, 2002.

BAUDRILLARD, J. La société de consommation. Saint Armand: Edition Denoël, 2005.

. L'échange impossible. Paris: Éditions Galilée, 1999.

EAGLETON, T. A ideologia da estética. Rio de Janeiro: Editora Jorge Zahar, 1993.

FRIGOTTO, G. Educação, crise do trabalho assalariado e do desenvolvimento: teorias em conflito. In: FRIGOTTO, G. (Org.). Educação e crise do trabalho: perspectivas de final de século. Petrópolis: Editora Vozes, 1998, p. 25-54.

GIL, J. Metamorfoses do corpo. Lisboa: Relógio d’Água, 1997.

HARVEY, D. O corpo como estratégia de acumulação. In: Espaços de esperança. São Paulo: Edições Loyola, 2000. p. 135-160.

JAMESON, F. Pós-modernismo: A lógica cultural do capitalismo tardio. São Paulo: Editora Ática, 2002.

KONDER, L. O marxista belicoso. Teoria e debate, n.39, 1998. Disponível em: $<$ http://www2.fpa.org.br/portal/modules/news/article.php?storyid=2299>. Acesso em: 16/8/2006.

LESSA, S. História e ontologia: a questão do trabalho. Critica Marxista, n. 20, p. 70-89, 2005.

LYOTARD, J. F. La condition postmoderne. Paris: Les éditions de minuit, 1979. 
MATTHIESEN, S. Q. A educação física e as práticas corporais alternativas: a produção científica do curso de graduação em educação física da Unesp - Rio Claro de 1987 a 1997. Motriz, v. 5, n. 2, p. 131-137, 1999.

MOOERS, C. Multiculturalism and the fetishim of difference. Joint center of excellence for research on immigration and settlement. Series Working Paper, n. 37. Toronto: 2005. Disponível em: < http://ceris.metropolis.net/Virtual\%20Library/WKPP\%20List/ WKPP2005/CWP37_Mooers_final.pdf >. Acesso em: 30/5/2005.

MCDONAGH, P. Analogue Bodies, Digital Minds. Mcgill Reporter, v. 37, n. 11, 2004. Disponível em: < http://www.mcgill.ca/reporter/37/05/hacking/>. Acesso em: 20/10/2006.

MCNALLY, D. Bodies of meaning. Studies on language, labor and liberation. Albany: State University of New York Press, 2001.

SFEZ, L. A saúde perfeita: crítica de uma nova utopia. São Paulo: Edições Loyola, 1996.

SIBILIA, P. O homem pós-orgânico: corpo, subjetividade e tecnologias digitais. Rio de Janeiro: Relume Dumará, 2002.

VILLAÇA, N.; GOÉS, F. Em nome do corpo. Rio de Janeiro: Rocco, 1998.

WOOD, E. M. O que é a agenda pós-moderna. In: WOOD, E.; FOSTER, J. (Orgs.). Em defesa da história: marxismo e pós-modernismo. Rio de Janeiro: Jorge Zahar Editora, 1999, p. 7-22. 